\title{
Expansão das licenciaturas em Educação do Campo: desafios e potencialidades
}

\section{Expansion of the degree in rural education: challenges and potentialities}

\author{
Monica Castagna Molina ${ }^{1}$
}

\begin{abstract}
RESUMO
Este artigo integra a Pesquisa realizada a partir do Observatório da Educação da Coordenação de Aperfeiçoamento de Pessoal de Nível Superior (CAPES), intitulada "Políticas da Expansão da Educação Superior no Brasil". Uma das frentes da expansão da Educação Superior tem se dado no âmbito da formação de educadores do campo, com a implementação de 42 cursos de uma nova modalidade de graduação, intitulada "Licenciatura em Educação do Campo". Se considerados os aspectos relativos à ampliação concreta da oferta de formação de educadores e a conquista dos fundos públicos do Estado para manutenção destas graduações esta expansão destes cursos permanentes pode ser tomada como vitória dos movimentos sociais. Porém, esta expansão também impõe uma série de desafios à manutenção dos princípios originais do Movimento da Educação do Campo. Quais os riscos e potencialidades desta ampliação? Com a perspectiva de apresentar elementos de reflexão sobre estas questões, este artigo elenca os riscos da descaracterização de aspectos estruturantes desta política e as potencialidades que se julgam conter neste processo de ampliação, que estão sendo analisadas na pesquisa "Políticas de Expansão da Educação Superior no Brasil".

Palavras-chave: Educação do Campo; Expansão da Educação Superior; Formação de Educadores.
\end{abstract}

\footnotetext{
ABSTRACT

This article is part of the research conducted from the Centre for Education of CAPES, entitled "Expansion of Higher Education Policies in Brazil". One

DOI: $10.1590 / 0104-4060.39849$

1 Universidade de Brasília. Campus Planaltina. Área Universitária n. 1. Vila Nossa Senhora de Fátima. Planaltina, Brasília, Distrito Federal, Brasil. CEP. 73000.
} 
of the important development in the expansion of higher education, has been the training of rural educators, with the implementation of 42 courses of a new type of degree, entitled "Degree in Rural Education." If we consider the aspects relating to the concrete enlargement of places for teacher training and the achievement of gaining public funds from the State to fund these courses, this expansion of these permanent courses can be taken as a victory for the social movements. However, this expansion also imposes a number of challenges to maintain the original principles of the Rural Education Movement. What are the risks and potentialities of this expansion? With the prospect of presenting thoughts on these issues, this article lists the risks of disfiguration of fundamental aspects of this policy and potentialities that are deemed to be contained within this expansion process, which are being analysed in the research "Political Expansion of Higher Education in Brazil".

Keywords: Rural Education; Expansion of Higher Education; Educator Training.

\section{Introdução}

O presente artigo integra a pesquisa "Políticas de Expansão da Educação Superior no Brasil”, cujo período de execução é de 2013 a 2017, realizada a partir do Observatório da Educação da Coordenação de Aperfeiçoamento de Pessoal de Nível Superior - CAPES.

Integrada por sete subprojetos e realizada articuladamente por pesquisadores de diversas Instituições de Ensino Superior - IES no país, o objetivo geral da referida pesquisa é analisar as Políticas de Expansão da Educação Superior no Brasil, a partir de 1995, considerando as mudanças econômicas, políticas e sociais em curso e as reformas institucionais advindas da Reforma do Estado brasileiro.

Como um dos sete subprojetos, está o Grupo de Pesquisa - GP que tem como foco a análise da expansão da Educação Superior do Campo e de suas contribuições para o desenvolvimento rural e para a sociedade nacional. Uma das frentes em que vem ocorrendo uma expansão da Educação Superior do Campo é no âmbito da formação de educadores, com a implementação de 42 cursos em IES brasileiras (relação anexa) de uma nova modalidade de graduação, concebida a partir da demanda dos movimentos sociais, intitulada "Licenciatura em Educação do Campo".

Essa ampliação, por sua vez, faz parte de uma das mais recentes políticas de Estado, lançada em 2012, e intitulada Programa Nacional de Educação do 
Campo - Pronacampo, que objetiva oferecer apoio técnico e financeiro aos estados, Distrito Federal e municípios para implementação da Política Nacional de Educação do Campo, devendo atender Escolas do Campo e Quilombolas, a partir de quatro eixos de ação: 1. Gestão e Práticas Pedagógicas; 2. Formação de Educadores; 3. Educação Profissional e Tecnológica; e 4. Infraestrutura.

É dentro do Eixo 2 que se localiza especificamente a ação do Estado responsável por apoiar e fazer acontecer a implantação dos 42 novos cursos de Licenciatura em Educação do Campo - LEDOC, através de um Subprograma intitulado "Programa de Apoio às Licenciaturas em Educação do Campo Procampo".

Este artigo tem como objetivo apresentar uma parte das questões desenvolvidas no primeiro ano da referida pesquisa, pelo Grupo que analisa a Expansão da Educação Superior no Campo, organizadas a partir dos desafios a serem enfrentados e das potencialidades que podem advir da expansão do Procampo, considerando-se o processo de implantação e consolidação desses 42 cursos permanentes de Licenciatura em Educação do Campo, nas instituições de ensino superior brasileiras.

Essa expansão poderá significar um relevante avanço dos princípios do Movimento da Educação do Campo, no âmbito da Educação Superior, ou, esta concepção educativa será engolida e subsumida na institucionalização que, necessariamente, se fará presente neste processo de crescimento? A presença dos movimentos sociais e sindicais do campo, que devem vir a ser parte dos educandos destas graduações, pode significar algum tipo de ruptura no intenso processo de mercantilização da produção do conhecimento que se tem presenciado na Educação Superior? A vinculação direta destes cursos de formação de educadores com as lutas dos camponeses pela sua permanência na terra e no território, e com a conquista das escolas neles existentes, se manterá neste processo de expansão?

Com a perspectiva de apresentar elementos para subsidiar a reflexão sobre essas questões, que estão sendo analisadas a partir da pesquisa "Políticas de Expansão da Educação Superior no Brasil", este artigo está organizado em quatro tópicos: no primeiro, se recupera resumidamente o contexto e o histórico da criação da Licenciatura em Educação do Campo; no segundo, se apresentam os princípios que orientam a matriz político-pedagógica deste curso; no terceiro, se discorre sobre os desafios de descaracterização de cinco aspectos considerados estruturantes desta política que podem advir com a expansão, cujos desdobramentos serão objeto de análise da pesquisa nos próximos anos; e por fim, apresentam-se ainda as potencialidades que se julgam conter neste processo de expansão, cuja materialização ou não nos próximos anos será também objeto de acompanhamento. 
Tanto os cinco pontos eleitos como desafios potencias de descaracterização, a partir desta expansão (promover o ingresso dos sujeitos camponeses na Educação Superior; garantir o protagonismo dos movimentos sociais do campo na sua execução; se vincular organicamente com as lutas e com as Escolas do Campo; materializar-se a partir da Alternância pedagógica; promover a formação do trabalho docente multidisciplinar, a partir das áreas de conhecimento); quanto as potencialidades que podem conter esta ampliação (consolidação da Educação do Campo como área de produção de conhecimento; acúmulo de forças para conquista de novas políticas e cursos; desencadeamento de novas lógicas para Organização Escolar e Método do Trabalho Pedagógico em Escolas do Campo; ampliação do acesso e uso de novas tecnologias nas Escolas do Campo), encontram o sentido de sua reflexão condicionados pela totalidade maior que os contém, qual seja: as tensões e contradições vivenciadas tanto pelo conjunto da expansão da Educação Superior no Brasil, quanto pelas tensões e contradições também vigentes no campo pela intensíssima expansão do modelo agrícola hegemônico estruturado a partir do agronegócio.

Assim, o detalhamento tantos dos desafios quanto das potencialidades que podem advir dessa expansão não terão sua análise em separado das graves condicionantes nas quais têm se operado a expansão da Educação Superior no Brasil.

Pois, se de 1995 a 2011, houve um crescimento de $283 \%$ das matrículas na Educação Superior no país, não obstante, permanece a inexorável necessidade de expandir fortemente este nível de ensino, já que somente $14,8 \%$ da população na faixa etária de 18 a 24 anos frequentavam algum tipo de curso superior em 2011. Porém, o que os dados explicitam é a imprescindível necessidade de dar qualidade a esta ampliação. Ainda mais grave que a ausência da qualidade é o sentido da expansão, que caminha aceleradamente na direção da rede privada, "que já cobre $74 \%$ das matrículas". Apesar deste crescimento, também ocorreram incentivos para o crescimento da rede pública, particularmente com a institucionalização do Programa de Apoio a Planos de Reestruturação e Expansão das Universidades Federais (REUNI), criado pelo Decreto $n^{\circ}$ 6.096/2007.

Todavia, o investimento público na expansão tem ficado muito aquém dos volumes necessários. Em síntese, de acordo com Mancebo et al. (2012),

[...] a contrapartida financeira tem sido insuficiente, de modo que a expansão da rede pública federal tem ocorrido com forte racionalização de recursos humanos e tem remetido à precarização e intensificação do trabalho docente, configurando uma expansão sem garantias de qualidade, que longe de corrigir a distribuição desigual dos bens educacionais, tende a aprofundar as condições históricas de uma educação superior elitista e excludente. (MANCEBO et al., 2012, p. 20). 
Da mesma maneira, o sentido da expansão da oferta das Licenciaturas em Educação do Campo não pode ser compreendido em separado dos intensos conflitos em torno do modelo de desenvolvimento hegemônico no campo na atualidade. Se o movimento da Educação do Campo compreende que a Escola do Campo deve ser uma aliada dos sujeitos sociais em luta para poderem continuar existindo enquanto camponeses; para continuar garantindo a reprodução material de suas vidas a partir do trabalho na terra, é imprescindível que a formação dos educadores que estão sendo preparados para atuar nestas escolas, considere, antes de tudo, que a existência e permanência (tanto destas escolas, quanto deste sujeitos) passa, necessariamente, pelos caminhos que se trilharão a partir dos desdobramentos da luta de classes; do resultado das forças em disputa na construção dos distintos projetos de campo na sociedade brasileira. (MOLINA, 2014).

A intensa e veloz redução do número de escolas existentes no território rural não pode ser vista em separado desse processo. Já existem teses de doutorado que demonstram a relação entre esses fenômenos, entre as quais destaca-se a que produziu um relevante estudo cartográfico no qual, a partir da sobreposição de mapas em que se registram os territórios do avanço do agronegócio na região Centro-Oeste, se demonstra a fagocitose das escolas rurais nos mesmos espaços, como o corolário da desterritorialização dos sujeitos camponeses pelo modelo hegemônico de organizar a agricultura baseado no agronegócio. (SOUZA, 2012).

\section{Contexto de criação e da ampliação do Procampo}

Uma das principais características e diferenças das políticas públicas de Educação Campo pautadas pelos movimentos sociais refere-se à sua participação e protagonismo, na concepção e elaboração de tais políticas. Durante a primeira década de sua história, dada a correlação de forças à época, o Movimento da Educação do Campo foi capaz de garantir este princípio, tendo forte participação na concepção e elaboração do Programa Nacional de Educação na Reforma Agrária - PRONERA (MOLINA, 2003); o Programa Nacional de Educação do Campo: Formação de Estudantes e Qualificação de Profissionais para Assistência Técnica, conhecido como Residência Agrária (MOLINA, 2009); no Saberes da Terra (ANTUNES-ROCHA, 2010), por exemplo.

Porém, esse protagonismo foi se perdendo e se transformando em mera representação formal, sem uma efetiva participação na concepção e no "modus operandi" das políticas públicas, à medida que foram se intensificando as 
mudanças do modelo de desenvolvimento no campo, a partir da consolidação do agronegócio no país.

Conforme análise do próprio Fórum Nacional de Educação do Campo FONEC, o período inicial do Movimento da Educação do Campo coincide com o período de transição que tem sido compreendido como "da crise do latifúndio a consolidação do Agronegócio". Foi, aliás, este período, de certa fragilidade da aliança das classes dominantes, que possibilitou o crescimento e avanço das lutas pelos direitos no campo. Conforme registrado no documento do Fórum, o Movimento reconhece que seu crescimento naquela época foi possível em função de determinada correlação de forças existentes no período:

[...] é possível afirmar que ocupamos um "vácuo" de transição de modelos (ajustes no modelo macro-econômico brasileiro, capitalista, neoliberal): entre a crise do latifúndio e a emergência do agronegócio os movimentos sociais de luta pela terra e pela Reforma Agrária ganharam ímpeto, conquistamos o Pronera e constituímos a Educação do Campo. A nova fase na política do capital para a agricultura, que iniciou com mais força a partir de 1999, abrindo um novo ciclo, gerou uma nova aliança das classes dominantes e um novo lugar para o campo no projeto de capitalismo brasileiro, fase que está nesse momento em plena vigência e força. (FONEC, 2012, p. 5).

Como parte daquela conjuntura, o Procampo é uma política de formação de educadores, conquistada a partir da pressão e das demandas apresentadas ao Estado pelo Movimento da Educação do Campo. Pautada desde a primeira Conferência Nacional por Uma Educação Básica do Campo - CNEC, realizada em 1998, a exigência de uma Política Pública específica para dar suporte e garantir a formação de educadores do próprio campo vai se consolidar como uma das prioridades requeridas pelo Movimento, ao término da II Conferência Nacional por uma Educação do Campo, realizada em 2004, cujo lema era exatamente "Por Um Sistema Público de Educação do Campo".

A partir da intensa cobrança dos movimentos sociais que seguiam pressionando para o atendimento das pautas da II CNEC, é instituído um Grupo de Trabalho que fica responsável pela elaboração da proposta que deveria subsidiar a Secretaria de Educação Continuada, Alfabetização, Diversidade e Inclusão SECADI, na proposição ao Ministério da Educação - MEC, de uma proposta de formação de educadores campo.

Os movimentos demandam e logram nesse período a conquista de um processo de elaboração bastante articulado com suas representações. Após os 
encontros específicos do GT, para dar forma ao primeiro desenho da política de formação de educadores do campo, foram realizadas também com suas representações alguns encontros em que submeteu-se ao debate a proposta elaborada, para chegar-se à versão a ser apresentada às várias instâncias do MEC responsáveis pela implementação do Programa, que finalmente aprovou o desenho das Licenciaturas em Educação do Campo. (MOLINA, 2014).

A implantação dessa política se inicia através de uma experiência piloto, com a construção de quatro cursos que foram realizados a partir dos convites efetuados pelo Ministério da Educação, a partir de indicações de instituições universitárias pelos movimentos sociais ligados à Educação do Campo (UFMG; UnB; UFBA e UFS), na audiência em que se apresentou a proposta da política a este coletivo.

Esse é um detalhe de diferença relevante a ser observado agora no processo de ampliação: da época do início do Procampo, foram convidadas a integrar a proposta universidades que já tinham experiências na oferta de cursos de Educação do Campo e parcerias com os movimentos sociais e sindicais, o que não se repetiu nesta ampliação dos 42 cursos, havendo, entre eles IES que nunca desenvolveram projetos de ensino, pesquisa ou extensão nesta área de conhecimento.

Com essas experiências piloto ainda em execução, a partir da imensa demanda de formação de educadores do campo e da pressão dos movimentos sociais, o MEC lança editais em 2008 e 2009, para que novas instituições passassem a ofertar a Licenciatura em Educação do Campo, sendo que a partir da concorrência a estes Editais, 32 universidades passaram a ofertar o curso, porém sem nenhuma garantia de sua continuidade e permanência, já que esta oferta através de Editais faz-se através da aprovação nas instituições de ensino superior de projetos especiais, tramitados e autorizados somente para oferta de uma turma.

Esse foi um dos pontos sobre os quais mais insistentemente houve questionamento dos movimentos. A demanda para formação de educadores do campo, além de ter que ser capaz de suprir o enorme passivo já existente, necessariamente deveria ser permanente para garantir o direito à educação aos sujeitos do campo, a partir de suas especificidades e necessidades.

Com a assinatura do Decreto 7.352, de 2010, que instituiu a Política Nacional de Educação do Campo, se impôs a exigência da elaboração de um Programa Nacional de Educação do Campo para dar materialidade às ações nele previstas, e instituiu-se, em 2012, outro GT, que também contou com a participação de membros dos movimentos sociais, para conceber as ações que integrariam o referido Programa. É preciso registrar que este contexto já é bastante diferenciado daquele vivenciado pelo GT de 2005-2006, que elaborou as 
diretrizes orientadoras das Licenciaturas em Educação do Campo, com espaço muito menor para um efetivo protagonismo dos movimentos sociais.

Embora bem aquém da demanda existente, o Pronacampo estabelece uma meta ambiciosa para três anos: formar 45 mil educadores do campo, quantitativo que deveria ser distribuído entre três estratégias de formação que ocorreriam simultaneamente: os próprios cursos do Procampo; os cursos desenvolvidos através da Plataforma Freire via Plano Nacional de Formação de Professores da Educação Básica - Parfor, e a terceira via mais problemática, através da Educação a Distância, via Universidade Aberta do Brasil UAB. Alvo de profundas e pertinentes críticas do Movimento da Educação do Campo, esta última estratégia não foi ainda iniciada, não sendo, porém o caso da oferta da formação de educadores do campo via Parfor, cujo crescimento tem sido expressivo. Já existem pesquisas (BITTENCOURT, 2013) que analisam a inadequação destes cursos aos educadores do campo, não sendo incorporadas em seu currículo as especificidades da formação de educadores que trabalharão com os camponeses.

\section{Principais características da Licenciatura em Educação do Campo}

Os cursos de Licenciatura em Educação do Campo têm como objeto a escola de Educação Básica, com ênfase na construção da Organização Escolar e do Trabalho Pedagógico para os anos finais do Ensino Fundamental e do Ensino Médio. Os cursos objetivam preparar educadores para, além da docência, atuar na gestão de processos educativos escolares e na gestão de processos educativos comunitários.

A organização curricular dessa graduação prevê etapas presenciais (equivalentes a semestres de cursos regulares), ofertadas em regime de Alternância entre Tempo Escola e Tempo Comunidade, tendo em vista a articulação intrínseca entre educação e a realidade específica das populações do campo. Esta metodologia de oferta intenciona também evitar que o ingresso de jovens e adultos na Educação Superior reforce a alternativa de deixar de viver no campo, bem como objetiva facilitar o acesso e a permanência no curso dos professores em exercício nas Escolas do Campo. (MOLINA; SÁ, 2011).

A matriz curricular proposta desenvolve uma estratégia multidisciplinar de trabalho docente, organizando os componentes curriculares a partir de quatro áreas do conhecimento: Artes, Literatura e Linguagens; Ciências Humanas e Sociais; Ciências da Natureza e Matemática e Ciências Agrárias. 
A habilitação de docentes por área de conhecimento tem como um dos seus objetivos ampliar as possibilidades de oferta da Educação Básica no campo, especialmente no que diz respeito ao Ensino Médio, mas a intencionalidade maior é a de contribuir com a construção de processos capazes de desencadear mudanças na lógica de utilização e de produção de conhecimento no campo, desenvolvendo processos formativos que contribuam com a maior compreensão dos sujeitos do campo da totalidade dos processos sociais nos quais estão inseridos. (CALDART, 2011).

Ao construir como perfil de habilitação da Licenciatura em Educação do Campo, simultaneamente, as três dimensões - a docência por área de conhecimento; a gestão de processos educativos escolares e a gestão de processos educativos comunitários - se idealizou esta perspectiva: promover e cultivar um determinado processo formativo que oportunizasse aos futuros educadores, ao mesmo tempo, uma formação teórica sólida, que proporcionasse o domínio dos conteúdos da área de habilitação para a qual se titula o docente em questão, porém, extremamente articulada ao domínio dos conhecimentos sobre as lógicas do funcionamento e da função social da escola e das relações que esta estabelece com a comunidade do seu entorno.

Ou seja, a formação por áreas de conhecimento deve desenvolver-se tendo como intencionalidade maior promover estratégias que contribuam para superar a fragmentação do conhecimento, criando, propondo e promovendo ações docentes articuladas interdisciplinarmente, associadas intrinsecamente às transformações no funcionamento da escola e articuladas, ainda, às demandas da comunidade rural na qual se insere esta escola. A proposta e o desafio é realmente materializar práticas formativas durante o percurso da Licenciatura em Educação do Campo que sejam capazes de ir desenvolvendo e promovendo nos futuros educadores as habilidades necessárias para contribuir com a consolidação do ideal de escola edificado por este movimento educacional protagonizado pelos camponeses nestes últimos 15 anos: uma Escola do Campo. (MOLINA, 2012).

Apostando na compreensão gramsciniana que entende a escola como um espaço em disputa, como importante lócus de produção de contra-hegemonia aos valores da sociedade capitalista, o movimento da Educação do Campo trabalha com a perspectiva de formar educadores camponeses que possam atuar nestas escolas como intelectuais orgânicos da classe trabalhadora (GRAMSCI, 1991) contribuindo, por sua vez, com a formação crítica dos educandos que passem por estas unidades escolares, dando-lhes condições de compreender os modelos de desenvolvimento do campo em disputa, como parte integrante da totalidade maior da disputa de projetos societários distintos, entre a classe trabalhadora e a capitalista. (MOLINA, 2014). 


\section{Os desafios que podem advir da Ampliação dos cursos de Licenciatura em Educação do Campo}

A partir das principais dificuldades enfrentadas nestes anos de execução das Licenciaturas em Educação do Campo, tanto pelas experiências piloto, quanto pelas que se seguiram, implantadas como projetos especiais a partir dos Editais da SECADI, de 2008 e 2009, bem como por aquelas que foram se tornando permanentes a partir de sua incorporação pelas universidades ofertantes, foram eleitos alguns pontos nevrálgicos de serem acompanhados pela pesquisa neste processo de ampliação, pois podem significar uma relevante descaracterização de aspectos considerados estruturantes desta política. São eles:

\section{a) As estratégias de ingresso dos sujeitos camponeses nas Licenciaturas}

Em relação às estratégias de ingresso, é fundamental estar atento que as Licenciaturas em Educação do Campo, necessariamente, devem garantir o ingresso dos sujeitos camponeses na Educação Superior. E, dada a histórica desigualdade na garantia do direito à educação aos povos do campo, que se traduz na extrema fragilidade das escolas no meio rural, é imprescindível que se garanta a realização de um vestibular específico, mantendo, necessariamente, o caráter de política afirmativa do Procampo.

Gaudêncio Frigotto (2011) destaca que é necessário localizar o tema das ações afirmativas não somente no plano ideal, "do contra ou a favor, do bom ou do ruim”, mas é necessário localizá-lo em nosso tempo histórico, no contexto real, terreno das inúmeras e imensas contradições sociais que enfrentamos na sociedade do capital, tanto no âmbito internacional, quanto, no Brasil do século XXI.

E, nessa perspectiva, do terreno das contradições, é que podemos compreender e situar as políticas afirmativas de Educação Superior para os camponeses, pois apesar da totalidade na qual elas estão contidas, onde há forte determinação dos organismos multilaterais para implantação deste tipo de políticas, há também importante componente da luta dos movimentos sociais do campo para sua conquista e implantação.

Frigotto (2011) alerta que no âmbito dos organismos internacionais, as políticas afirmativas são incentivadas como parte das estratégias de desviar o foco dos debates e das lutas das dimensões fundamentais de uma agenda de reestruturação da Universidade pública, como, por exemplo, a autonomia universitária; as fontes de financiamento; os mecanismos de desmonte de seu 
caráter público, que tem sido implementado de maneira tanto explícita quanto sorrateira, através de critérios mercantis de gestão e de diversas estratégias de privatização por dentro das instituições, através de perversos mecanismos de captação dos recursos via mercado, retirando cada vez mais do Estado a obrigação completa de seu financiamento.

Para além dessas intencionalidades contidas na implantação das políticas afirmativas, faz-se necessário estar alerta à outra ainda mais perniciosa, que não deve ser ignorada: estas estratégias de inclusão cumprem também o objetivo de "[...] mascarar o antagonismo de classe, reduzindo-os à questão de disparidades e diferenças". (FRIGOTTO, 2011, p. 20). Portanto, uma leitura crítica da necessidade e defesa das políticas afirmativas para a garantia do acesso à Educação Superior para camponeses exige situá-las simultaneamente, "[...] à luz das reformas estruturais do Estado, como da exigência metabólica do capital e no âmbito da luta de classes". (FRIGOTTO, 2011, p. 21).

Esse é caso do Procampo, conquistado a partir de intenso processo de luta e organização dos movimentos sociais e sindicais, que tem proporcionado a ampliação do acesso à Educação Superior para os sujeitos do campo, cujo taxa de escolarização líquida neste nível de ensino (3,2\%) é praticamente cinco vezes menor que a do meio urbano (19,8\%), conforme dados do Instituto Nacional de Estudos e Pesquisas Educacionais Anísio Teixeira - INEP de 2012.

Convém relembrar, ainda, importantes números da realidade rural, que reforçam essa necessidade: o precaríssimo acesso dos docentes do meio rural à educação de nível superior. De acordo com dados da Pesquisa Nacional por Amostra de Domicílios - PNAD, de 2007, do total de funções docentes no país, atuando na modalidade regular do Ensino Fundamental e Médio, o meio rural detém $16,7 \%$, ou seja, 311.025 profissionais em exercício, dos quais $61 \%$ não apresentam formação de nível superior, o que significa um contingente de aproximadamente 178 mil professores sem a formação adequada. (MOLINA; SÁ, 2011).

Porém, embora o Procampo tenha sido idealizado para enfrentar esses índices e funcionar como uma política capaz de dinamizar e ampliar o acesso dos educadores do campo à universidade, um dos desafios enfrentados por várias instituições que ofertam a Licenciatura em Educação do Campo é resistir às exigências feitas por parte das universidades, de fazer com que o acesso à Educação Superior para os sujeitos do campo, nestas Licenciaturas, se dê através de vestibular universal, excluindo a possibilidade do ingresso por turmas com critérios específicos, como por exemplo, a vinculação de moradia no próprio campo e a atuação em escolas do campo. Esta pretensa universalidade de acesso descaracterizaria totalmente o propósito inicial idealizado para essa política pública, no sentido de vir a suprir a enorme lacuna nos patamares de formação 
dos educadores do campo e de contribuir para elevar o nível de escolaridade dos jovens do campo, ainda que não sejam educadores.

Portanto, conseguir manter o perfil específico de ingresso dessas Licenciaturas é uma tarefa coletiva a ser enfrentada continuamente, não só nos embates com as Procuradorias Jurídicas das universidades, mas com o conjunto da sociedade, no sentido de ampliar a compreensão sobre a necessidade da intervenção do Estado para promover ações que de fato sejam capazes de promover a igualdade de acesso aos direitos educacionais. (MOLINA; SÁ, 2011).

\section{b) O protagonismo dos movimentos sociais}

Outro fator de risco extremamente importante para a manutenção dos princípios da Educação do Campo nessas novas Licenciaturas diz respeito à presença e à participação dos Movimentos Sociais, enquanto sujeitos coletivos, nessas graduações.

Aposta-se na potencialidade dessa Licenciatura, dada a concepção de sua matriz formativa, de contribuir com a formação de intelectuais orgânicos da classe trabalhadora, comprometidos com as lutas e com as transformações das condições de vida no campo. Para tanto, faz-se necessário desenvolver processos formativos capazes de promover e elevar o nível de consciência de classe daqueles que dela participam. E, parte fundamental deste processo, é não só o acesso ao conhecimento científico, mas, principalmente, a participação nos próprios processos da luta de classes no campo, que vem se acirrando cada vez mais, em função da intensificação da lógica de acumulação do capital no meio rural, com a intensa ampliação do agronegócio.

Conforme já analisado por vários autores (CALDART, 2009; MOLINA, 2010), nos últimos anos percebeu-se uma mudança relevante em uma das principais características da Educação do Campo: o protagonismo dos movimentos na execução das políticas públicas por eles conquistadas. Para que estas novas graduações possam cumprir os desafios para os quais foram desenhadas, como por exemplo, contribuir para formar educadores do campo capazes de promover a vinculação das Escolas do Campo com as lutas dos sujeitos camponeses para permanecer nestes territórios, esta presença dos Movimentos Sociais é imprescindível.

Por mais que os docentes que atuam nas Licenciaturas em Educação do Campo se comprometam com a promoção de uma educação crítica e emancipatória, é a vinculação concreta com as lutas sociais e coletivas, que, de fato, promoverão uma formação diferenciada aos educadores que dela participam. Só o debate teórico sobre as lutas não forma os lutadores do povo. É a inserção 
concreta nas lutas pela terra; pela manutenção dos territórios; pelo não fechamento e pela construção de novas escolas; pela não invasão do agronegócio nos assentamentos; pelo acesso à água; pela promoção de práticas agroecológicas e pela garantia da soberania alimentar, enfim, por tantos e tão relevantes desafios concretos que enfrentam os camponeses, que, podem, verdadeiramente, dar sentido à concepção e ao perfil de educadores do campo, dignos deste nome, para o qual foi concebida a proposta de formação das Licenciaturas em Educação do Campo.

\section{c) A vinculação com as Escolas do Campo}

Entre os desafios postos ao processo de ampliação das Licenciaturas está o de garantir que sua realização se faça profundamente vinculada às escolas existentes nos territórios de origem dos educandos que a estão cursando, objetivando construir, junto com a participação dos movimentos sociais e sindicais nessas unidades educativas, de fato, Escolas do Campo, tal qual conceito construído pelo Movimento da Educação do Campo nestes últimos 15 anos.

Essa nova modalidade de graduação, que nasce a partir da luta dos movimentos sociais do campo para conquistar uma política específica de formação de educadores para atuar nas escolas do território rural, tem, exatamente, como maior intencionalidade, a perspectiva de formar um docente capaz de promover um profundo vínculo entre as tarefas específicas da escola e as demandas da comunidade durante sua realização.

Se, de uma maneira geral, espera-se que a escola seja capaz de promover a socialização das novas gerações e transmitir os conhecimentos historicamente acumulados, espera-se também, no Movimento da Educação do Campo, que ela seja capaz de tornar-se uma aliada dos camponeses em luta para permanecer no seu território, existindo como tais, enquanto camponeses. É imprescindível formar educadores do campo capazes de indagar a realidade e buscar os elementos que ampliem sua compreensão sobre o porquê se fecharam, de acordo com dados do próprio INEP, mais de 32 mil escolas rurais nos últimos dez anos (de 102 mil, em 2002 para 70 mil em 2013).

O processo de fagocitose das escolas nesse contexto está indissociavelmente relacionado ao destino do campo, e do debate central a ele subjacente: a ausência de trabalho no campo, em função da intensíssima incorporação de novas tecnologias, e de cada vez mais trabalho morto. Enfrentar, portanto, o desafio do fechamento das escolas do campo implica, necessariamente, enfrentar o modelo de desenvolvimento hegemônico do capital, não havendo saída senão nas lutas por sua superação. (MOLINA, 2014). 


\section{d) A concepção de Alternância a ser implementada nas Licenciaturas e a compreensão e execução da formação por área de conhecimento}

Os riscos que se têm podido perceber em alguns cursos de Educação Superior ofertados em Alternância para os sujeitos do campo têm se referido ao tipo de prática de Tempo Comunidade que tem se materializado nessas graduações. Este tipo de prática tem reduzido os cursos em Alternância aos processos formativos que ocorrem somente no Tempo Escola, sendo simplesmente ignorado como tempo e espaço de aprendizagem as condições de vida e trabalho no campo durante os períodos do Tempo Comunidade, não havendo intencionalidade de ação e planejamento para participação e realização de atividades individuais e coletivas, nos territórios rurais de origem dos educandos.

Consequentemente, as tensões e as contradições da produção material da vida que neles ocorrem acabam não sendo incorporadas à dinâmica do currículo das Licenciaturas, ficando estas questões ausentes dos Tempos Escola subsequentes. A intencionalidade da concepção das Licenciaturas em Educação do Campo foi e é ser capaz de construir com os educandos em formação a experiência de um currículo vivo, que tenha como preocupação central a socialização dos conhecimentos científicos historicamente acumulados, sabendo e entendendo que a escola é um espaço fundamental para isto, porém, sem ignorar as dinâmicas e as transformações que ocorrem na vida dos educandos que estão nestes processos de formação docente, trazendo-os como parte da matéria-prima da aprendizagem.

Se, por um lado, a Alternância guarda imenso potencial de ressignificar os processos de produção de conhecimento, nas situações nas quais promove-se verdadeiramente uma intensa troca de tempos e espaços de aprendizagens, nos quais as diferentes dimensões da vida integram-se aos processos de produção do conhecimento, por outro, se desconsiderados os pressupostos de valorização dos saberes dos sujeitos e integração da produção material nos processos de ensino-aprendizagem, e da não presença da Universidade em diferentes tipos de atividades no Tempo Comunidade, a Alternância na Educação Superior perde parte relevante de seu sentido.

Ao contrário disso, a proposta é vivenciar e construir um processo contínuo de educação, onde a realidade social é a matéria-prima central da formação desses educadores. Isto, sem, entretanto, resvalar para outro extremo que considera estar apenas na realidade as questões que esses educandos têm direito de aprender. Para tanto, a Alternância tem sido uma ferramenta metodológica fundamental, pois possibilita aproximar a Universidade dos processos de produção de conhecimento dessas contradições reais nas quais os sujeitos do campo estão inseridos durante o processo contínuo de materialização e construção da sua vida.

Necessariamente, a proposta político-pedagógica das Licenciaturas do Campo realiza-se a partir da Alternância. E, embora saibamos haver uma grande hetero- 
geneidade entre as universidades que têm trabalhado com Educação do Campo, se realizada a partir dos princípios originários do Movimento, o Tempo Comunidade guarda imenso potencial de contribuição para transformação dos processos formativos dos educadores do campo. Se, de fato, materializa-se a presença dos docentes das diferentes áreas de conhecimento nas quais são ofertadas as habilitações nas Licenciaturas, nas Escolas do Campo, trabalhando junto com os educadores que nelas atuam, e envolvendo neste trabalho os educandos em formação na Licenciatura, novos espaços de troca e de ressignificação dos conhecimentos, envolvendo estes três diferentes conjuntos de saberes docentes, se interligam.

A formação por áreas de conhecimento é, sem dúvida, uma estratégia formativa extremamente difícil de materializar, apresentando inúmeros riscos, porém, sendo também portadora de relevantes potencialidades, se houver de fato intencionalidade e vontade de construir novos caminhos para o uso do conhecimento científico, colocando-o a serviço das transformações das condições de vida dos sujeitos do campo.

Um dos maiores riscos dessa estratégia está na precarização da formação docente, que pode ocorrer a partir da supressão de conhecimentos disciplinares fundamentais ao aprendizado de determinados conteúdos, ou mesmo, do acesso a eles de maneira superficial e insuficiente para garantir o seu verdadeiro domínio. E, há ainda um fator relevante a se somar ao imenso desafio desta estratégia formativa, no caso das Licenciaturas em Educação do Campo, a formação em Alternância, o que demanda um sábio exercício de planejamento dos conteúdos necessários a serem socializados em cada Tempo Escola e dos períodos disponíveis para tanto.

Assim, um dos grandes desafios é de fato a realização de um amplo trabalho prévio de organização e planejamento coletivo entre os docentes das áreas de habilitação para a socialização dos conteúdos a serem trabalhados com os educandos. Porém, o que é fundamental é que a concepção do trabalho interdisciplinar a ser desenvolvido nas Licenciaturas em Educação do Campo, para atender às intencionalidades para o qual foi concebido, é que ele se dê a partir da materialidade dos próprios problemas reais e concretos a serem enfrentados no campo e não apenas e tão somente a partir da abstração, da articulação entre os conceitos das áreas das ciências. (FRIGOTTO, 2008; FREITAS, 2010).

\section{Potencialidades da ampliação}

A ampliação permanente de 42 novos cursos de Licenciatura em Educação do Campo pode ser tomada como uma importante vitória dos movimentos 
sociais se considerados os aspectos relativos à ampliação concreta da oferta de formação de educadores; a conquista dos fundos públicos do Estado para manutenção dessas graduações e institucionalização da Educação Superior em Alternância como forma permanente de garantir a oferta deste nível de ensino para os camponeses, com vestibulares anuais.

Mas, além dessas características, alguns outros aspectos estão sendo observados na Pesquisa sobre a Expansão da Educação Superior, no âmbito da ampliação da oferta da Licenciatura em Educação do Campo, considerados como potencialidades que podem conter esta ampliação. São eles:

\section{a) Consolidação da Educação do Campo como área de produção de conhecimento}

Para cumprir a meta do Pronacampo, de formar 15 mil educadores do campo presencialmente, há um ponto considerado muito importante para o avanço e a consolidação da Educação do Campo no nível superior, cuja materialização, porém, está eivada de riscos. Trata-se da conquista de 600 vagas de concurso para docentes no nível superior, para atuarem nas Licenciaturas em Educação do Campo. Supondo-se que esta área de conhecimento seja o foco de seus trabalhos de ensino; pesquisa e extensão, não seria uma força material importante para a Educação do Campo poder contar com estes novos 600 docentes, trabalhando com a formação de educadores e fazendo desta graduação um relevante espaço de pesquisa e produção de conhecimento sobre as especificidades do processo formativo proposto por essas Licenciaturas e sobre as potencialidades das Escolas do Campo nas lutas de resistência camponesa?

Esse ingresso poderá significar uma ampliação do debate e da inserção das contradições ligadas à questão agrária na agenda de pesquisa das instituições nas quais a Licenciatura em Educação do Campo torna-se um curso permanente, com corpo docente fixo e entrada anual de estudantes camponeses?

A existência de vários cursos de Licenciatura em Educação do Campo pode também vir a significar um relevante espaço de produção de conhecimento, não só no âmbito dessas graduações, mas também em inovadoras experiências coletivas de oferta de pós-graduação, que tem sido estimulada a partir das dificuldades enfrentadas pelas IES que já vêm trabalhando com as Licenciaturas, nas mesmas áreas de habilitação a partir do trabalho coletivo entre elas.

Uma importante experiência nesse sentido vem sendo desenvolvida em parceria entre as universidades que ofertam a área de habilitação de Ciências Naturais, articulada coletivamente entre a Universidade Brasília; a Universidade Federal de Santa Catarina; a Universidade Federal de Minas Gerais e a Universidade Federal do Pará, que estão organizando a oferta de uma Especialização 
em Trabalho Docente Interdisciplinar na área de Ciências Naturais nas Escolas do Campo, para os egressos das Licenciaturas em Educação do Campo destas instituições.

Tem se percebido que está em curso um rico processo de criação de grupos interinstitucionais de pesquisa nas áreas de habilitação, com relevante potencial de geração de conhecimentos e estratégias de ensino-aprendizagem a partir das áreas de conhecimento, gerando novas possibilidades de trabalho nas Escolas do Campo.

\section{b) Espaço de acúmulo de forças para conquista de novas políticas públicas}

A ampliação permanente de 42 novos cursos de Licenciatura em Educação do Campo pode apontar para um acúmulo de forças para disputar, dentro do próprio Estado, outras políticas que, necessariamente, serão requeridas para a oferta deste nível de ensino a partir da Alternância, como por exemplo, uma política para construção de alojamentos para os sujeitos do campo que estarão nestas universidades durante os períodos de Tempo Escola?

Conforme foi possível observar na primeira reunião realizada com todas as 42 novas universidades que estão ofertando a Licenciatura em Educação do Campo, convocada pela SECADI e pela CAPES, e realizada em Brasília em setembro de 2013, com a presença e a participação dos integrantes do FONEC, se este sujeito coletivo que representa o Movimento da Educação do Campo conseguir protagonizar e cultivar uma articulação entre as IES que estão ofertando estas graduações, puxado pela força dos movimentos sociais e sindicais que o integram, poder-se-á estar em formação um relevante espaço de acúmulo de força e de pressão organizada sobre o Estado.

As Licenciaturas em Educação do Campo, como cursos permanentes, poderão também significar, a exemplo do que já vem ocorrendo com os cursos existentes desta nova modalidade de graduação, importantes espaços para desenvolver com as Escolas do Campo outros projetos além do ensino, envolvendo-as também em projetos de extensão e pesquisa, como por exemplo, o Programa Institucional de Bolsa de Iniciação à Docência - PIBID Diversidade, e o Observatório da Educação do Campo.

Poderiam também as Licenciaturas em Educação do Campo vir a ser importantes espaços de apoio para a conquista de novos cursos superiores para os camponeses, em áreas do conhecimento que são fundamentais para a construção de uma nova matriz tecnológica de produção no campo, ligadas, por exemplo, à promoção da agroecologia e à soberania alimentar, tal como vem ocorrendo com os cursos de Residência Agrária? 


\section{c) Ampliação do acesso e uso das Novas Tecnologias nas Escolas do Campo}

Outra potencialidade que se tem observado no decorrer da oferta das Turmas de Licenciatura em Educação do Campo é a da ampliação do acesso e do uso das novas tecnologias por esses docentes em formação. As demandas decorrentes dos trabalhos acadêmicos requeridos nestas graduações, tanto no Tempo Escola quanto no Tempo Comunidade, exige que os educadores em formação incorporem o uso das novas tecnologias nas suas atividades.

Embora o acesso a elas seja ainda bastante precário nas Escolas do Campo, os educadores que nelas atuam, ao cursarem as Licenciaturas, vão incorporando seu uso, tanto no próprio processo de formação, quanto nas pesquisas e nos trabalhos de organização didática com seus alunos nas Escolas do Campo nas quais atuam, conforme comprovou a tese de doutorado de Márcio Ferreira, intitulada "Comunicação e tecnologias da informação na formação de educadores para ampliação das perspectivas críticas dos sujeitos na Licenciatura em Educação do Campo da UnB".

Também como parte da ampliação do acesso às novas tecnologias, tem se observado que a presença dos educadores das escolas do campo nas universidades oportuniza também o acesso a outras linguagens, que têm sido incorporadas nos trabalhos nas Escolas do Campo, como por exemplo, o trabalho com a produção de vídeos e documentários, feitos pelos próprios estudantes da LEDOC, a partir da formação para tal, viabilizada em projetos de extensão realizados no decorrer da oferta da Licenciatura em Educação do Campo, com destaque para a realização de atividades formativas não só no Tempo Escola para o uso deste recurso, mas, principalmente, no Tempo Comunidade.

Esse é o caso, por exemplo, do Projeto "Formação de Educadores do Campo para o Uso de Tecnologias de Informação e Comunicação", desenvolvido durante dois anos, com quatro turmas de estudantes da Licenciatura em Educação do Campo da UnB - Universidade de Brasília, sob a coordenação do prof. Rafael Villas Bôas, em parceria com o Ministério das Comunicações. Dentre vários objetivos do Projeto, importa destacar aqui dois deles, quais sejam: 1) promover a formação de educadores que cursam a Licenciatura em Educação do Campo da UnB, no uso das Tecnologias da Informação e Comunicação (TIC), proporcionando capacidade de análise crítica das formas hegemônicas de representação da realidade e capacidade técnica de produção e ensino no campo do audiovisual e do domínio das TIC, para seu uso nas Escolas do Campo; e 2) realizar Oficinas de formação e formação audiovisual nas comunidades rurais de origem dos educadores da Licenciatura em Educação do Campo, especialmente voltadas para a juventude rural do entorno da Escolas do Campo destas 
localidades, desenvolvendo junto com estes jovens as habilidades de filmagem, edição, projeção e divulgação de vídeos via internet.

A partir de intenso trabalho de formação, tanto no Tempo Escola, como no Tempo Comunidade, conforme dito anteriormente, o referido projeto obteve resultados relevantes, para qualificação docente, conforme registrado no Relatório Final, onde afirma-se que

No âmbito da formação escolar e dos espaços de formação e cultura das comunidades, os estudantes da educação do campo já podem atuar como professores e ou formadores analisando criticamente a linguagem audiovisual, e os padrões hegemônicos de representação da realidade, operados pela Indústria Cultural. (VILLAS BÔAS et al., 2013, p. 9).

Outro aspecto ainda muito relevante do projeto foi o fato de ter contribuído para promover a qualificação do olhar dos educandos do campo que dele partiparam, para as várias estratégias de uso da linguagem audiovisual, cultivando nestes um olhar crítico sobre as "[...] representações audiovisuais que já foram produzidas sobre eles, que em muitos casos resvala para o estereótipo do exotismo". (VILLAS BÔAS et al., 2013, p. 10). Conforme os dados do Relatório Final, entre outros importantes resultados alcançados destacam-se ainda o uso dos recursos audiovisuais como um meio de elaboração da memória coletiva das comunidades camponesas, bem como um recurso político de elaboração dos problemas e exposição de denúncias - a produção audiovisual pode atuar nas diversas frentes de conflito existentes nos quilombos e assentamentos -, como a denúncia das condições precárias das escolas do campo e quilombolas; a denúncia dos crimes ambientais, entre outros.

\section{REFERÊNCIAS}

ANTUNES-ROCHA, M. I. et al. (Orgs.). Da Educação Rural à Educação do Campo: conceitos, práticas e marcos legais. Belo Horizonte: UFMG - Faculdade de Educação, 2010.

BARBOSA, A. I. C. A Organização do Trabalho Pedagógico na Licenciatura em Educação do Campo/UnB: do projeto às emergências e tramas do caminhar. Tese (Doutorado em Educação) - PPGE, UnB, Brasília, 2012. 
BRASIL. MEC. Censo Escolar 2013. Brasília: Instituto Nacional de Estudos e Pesquisas Educacionais Anísio Teixeira, 2013.

CALDART, Roseli Salete. Educação do Campo: notas para uma análise de percurso. Trab. Educ. Saúde [online], v. 7, n.1, p. 35-64, 2009.

CALDART, R. S. Licenciatura em Educação do Campo e projeto formativo: qual o lugar da docência por área? In: MOLINA, M. C.; SÁ, L. M. (Orgs.). Licenciaturas em Educação do Campo - Registros e reflexões a partir das experiências piloto. Belo Horizonte: Autêntica, 2011.

FREITAS, L. C. A Escola Única do Trabalho: explorando os caminhos de sua construção. Cadernos do ITERRA, Veranópolis - RS, n. 15, set. 2010.

FONEC. Notas para análise do momento atual da educação do campo. In: SEMINÁRIO NACIONAL, 2012, Brasília. Anais... Brasília, 2012. (digitalizado).

FRIGOTTO, G. Prefácio. In: FIGUEREIDO, E. Ações afirmativas na Educação Superior: políticas de inclusão ou exclusão? Bahia: UEFS Editora, 2011. p. 17-24.

FRIGOTTO, G. Interdisciplinaridade como necessidade e como Problema nas Ciências Sociais. Revista Centro de Educação e Letras, v. 10, n. 1, p. 41-62, 2008.

GRAMSCI, A. Os Intelectuais e a Organização da Cultura. Rio de Janeiro. Ed. Civilização Brasileira, 1991.

MANCEBO, D. Diversificação do ensino superior no Brasil e qualidade acadêmico-crítica. In: OLIVEIRA, J. F.; CATANI, A. M.; SILVA JUNIOR, J. R. (Orgs.). Educação Superior no Brasil - tempos de internacionalização. São Paulo: Xamã, 2010.

MANCEBO, D.; BITTAR, M.; CHAVES, V. L. J. (Orgs.). Educação superior: expansão e reformas educativas. Maringá: Eduem, 2012.

MOLINA, M. C. A contribuição do PRONERA na construção de políticas públicas de Educação do Campo e desenvolvimento sustentável. Tese (Doutorado em Desenvolvimento Sustentável) - Universidade de Brasília, Brasília, DF, 2003.

MOLINA, M. C. Análises de Práticas contra-hegemônicas na formação de Educadores: reflexões a partir do Curso de Licenciatura em Educação do Campo. In: SOUZA, José Vieira et al. (Orgs.). O método dialético na pesquisa em educação. Campinas, SP: Editora Autores Associados, 2014. p. 263-290.

MOLINA, M. C. Escola do Campo. In: CALDART, Roseli S. et al. (Orgs.). Dicionário da Educação do Campo. São Paulo: Escola Politécnica de Saúde Joaquim Venâncio; Expressão Popular, 2012.

MOLINA, M. C. Reflexões sobre o significado do protagonismo dos Movimentos Sociais na construção de Políticas Públicas de Educação do Campo. In: MOLINA, M. C. (Org.). Educação do Campo e Pesquisa II - Questões para Reflexão. Brasília: Ed. NEAD, 2010. p. 137-149. 
MOLINA, M. C. Residência Agrária - Concepções e Estratégias. In: MOLINA, M. C.; ESMERALDO, G. G. S. L; NEUMANN, P. S; BERGASMACO, S. M. P. P. (Orgs.). Educação do Campo e Formação Profissional: a experiência do Programa Residência Agrária. Brasília: MDA, 2009. p. 17-28.

MOLINA, M. C.; SÁ, L. M. A Licenciatura em Educação do Campo da Universidade de Brasília: Estratégias Político Pedagógicas na formação de educadores do campo. In: UFMG. UnB. UFS. UFBA. (Orgs.). Licenciaturas em Educação do Campo - Registros e reflexões a partir das experiências piloto. Belo Horizonte: Autêntica Editora, 2011. p. 35-64.

SANTOS, S. P. A concepção de Alternância da Licenciatura em Educação do Campo da Universidade de Brasília. Dissertação (Mestrado) - PPGE, UnB, Brasília, 2012.

SOUZA, F. E. As "geografias" das Escolas do Campo em Goiás: instrumento para valorização do território camponês? Tese (Doutorado) - PPGeo, UNESP, 2012.

VILLAS BÔAS, R. et al. Relatório Final do Projeto Formação de Educadores do Campo para o Uso de Tecnologias de Informação e Comunicação. Brasília: CETEC, $\mathrm{UnB}, 2013.170 \mathrm{p}$.

\section{Anexo:}

\begin{tabular}{|c|c|c|}
\hline \multicolumn{2}{|r|}{$\begin{array}{l}\text { UNIVERSIDADES E INSTITUTOS FEDERAIS COM CURSOS DE } \\
\text { LICENCIATURA EM EDUCAÇÃO DO CAMPO }\end{array}$} & Editais / Anos \\
\hline AP & Universidade Federal do Amapá & $2008 / 2009 / 2012$ \\
\hline PA & Universidade Federal do Pará - Campus Abaetetuba & 2012 \\
\hline PA & Universidade Federal do Pará - Campus Altamira & $2009 / 2012$ \\
\hline PA & Universidade Federal do Pará - Campus Camisa & $2009 / 2012$ \\
\hline PA & Universidade Federal do Pará - Campus Marabá & 2012 \\
\hline RO & Universidade Federal de Rondônia & 2012 \\
\hline RR & Universidade Federal de Roraima & 2012 \\
\hline TO & Universidade Federal de Tocantins - Campus de Arrais & 2012 \\
\hline TO & Universidade Federal de Tocantins - Campus de Tocantinópolis & 2012 \\
\hline DF & Universidade de Brasília - UNB & $2008 / 2009 / 2012$ \\
\hline GO & Universidade Federal de Goiás - Campus Catalão & 2012 \\
\hline GO & Universidade Federal de Goiás - Campus Cidade de Goiás & 2012 \\
\hline MS & Universidade Federal da Grande Dourados & 2012 \\
\hline MS & Universidade Federal de Mato Grosso do Sul & 2012 \\
\hline MT & $\begin{array}{l}\text { Instituto Federal Educação Ciência Tecnologia MT - Campus São } \\
\text { Vicente Serra }\end{array}$ & 2012 \\
\hline ES & Universidade Federal do Espírito Santo & 2012 \\
\hline
\end{tabular}

(Continua) 
(Conclusão)

\begin{tabular}{|l|l|l|}
\hline ES & Universidade Federal do Espírito Santo - Campus São Mateus & 2012 \\
\hline MG & Universidade Federal de Viçosa & 2012 \\
\hline MG & Universidade Federal do Triângulo Mineiro & 2012 \\
\hline MG & Universidade Federal dos Vales do Jequitinhonha e MUCURI & 2012 \\
\hline MG & $\begin{array}{l}\text { Instituto Federal de Educação, Ciência e Tecnologia do Norte de } \\
\text { Minas Gerais }\end{array}$ & $2008 / 2012$ \\
\hline RJ & Universidade Federal Fluminense & 2012 \\
\hline RJ & Universidade Federal Rural do Rio de Janeiro & 2012 \\
\hline MA & Universidade Federal do Maranhão & $2008 / 2009 / 2012$ \\
\hline MA & Instituto Federal de Educação, Ciência e Tecnologia do Maranhão & $2009 / 2012$ \\
\hline PB & Universidade Federal do Paraíba & 2012 \\
\hline PI & Universidade Federal do Piauí - Campus Cinobelina Elvas & 2012 \\
\hline PI & Universidade Federal do Piauí - Campus Floriano & 2012 \\
\hline PI & Universidade Federal do Piauí - Campus Picos & 2012 \\
\hline PI & Universidade Federal do Piauí - Campus Teresina & 2012 \\
\hline RN & Universidade Federal Rural do Semiárido & 2012 \\
\hline PR & Universidade Federal do Paraná - Litoral Sul & 2012 \\
\hline PR & Universidade Tecnológica Federal do Paraná & $2009 / 2012$ \\
\hline RS & Universidade Federal da Fronteira do Sul - Laranjeiras do Sul & 2012 \\
\hline RS & Universidade Federal da Fronteira do Sul - Campus Erechim & 2012 \\
\hline RS & Universidade Federal do Pampa & 2012 \\
\hline RS & Universidade Federal do Rio Grande do Sul & 2012 \\
\hline RS & Universidade Federal do Rio Grande & 2012 \\
\hline RS & Instituto Federal de Farroupilha & 2012 \\
\hline SC & Universidade Federal de Santa Catarina & $2008 / 2009 / 2012$ \\
\hline SC & $\begin{array}{l}\text { Instituto Federal de Educação, Ciência e Tecnologia de SC - } \\
\text { Canoinhas }\end{array}$ & 2012 \\
\hline
\end{tabular}

Texto recebido em 13 de fevereiro de 2015. Texto aprovado em 05 de março de 2015. 